\title{
The Role of Collusive Dynamics in the Occurrence of Organizational Crime: A Psychoanalytically Informed Social Psychological Perspective
}

\author{
Sandra Schruijer \\ Utrecht University School of Governance, Utrecht University, Bijlhouwerstraat 6, 3511 ZC Utrecht, \\ The Netherlands; s.g.l.schruijer@uu.nl
}

Received: 30 April 2018; Accepted: 21 June 2018; Published: 27 June 2018

\begin{abstract}
This short reflective paper discusses collusion from a psychoanalytically informed social psychological perspective. From this perspective, collusion represents a non-conscious group dynamic in which the participants 'play together' to keep a threatening or painful reality out of awareness. To illustrate the dynamics, two examples from the world of infrastructure and from higher education are provided. Although collusion in itself is not criminal, it may lead to neglectful or criminal behavior. Since it is a system-level phenomenon, holding individuals accountable will not end the dynamics.
\end{abstract}

Keywords: collusion; group dynamics; psychology; psychoanalysis; systems-psychodynamics

\section{Introduction}

Corporate or organizational crimes are defined as "illegal or harmful acts, committed by legitimate organizations or their members, for the benefit of these organizations" (Call for Papers). Examples of these crimes include financial manipulation, accounting fraud, cartels, bribery, environmental harms and corporate human rights violations. In this paper, I will focus on the phenomenon of collusion, which refers to a secret agreement between two or more parties to realize a fraudulent or illegal goal (American Dictionary of the English Language). In economic science, collusion represents a secret agreement between companies, which is often unwritten and manifests itself in cartels and implicit price agreements with unfair competition as a consequence (Ayres 1993). In policy sciences, such conspiring involves civil servants committing civil crimes (Van den Heuvel 2005). The phenomenon of collusion that I will be addressing derives from social psychology and from psychoanalysis. This collusion pertains to non-conscious relational dynamics between two or more parties (individuals, groups or organizations) that 'play together' so as to keep a threatening or painful reality out of awareness. Rather than outsiders being unknowing of secretive deals, as in cartels, it are now the protagonists themselves that are unaware of their collusive dynamics. Below, I will first define the concept of collusion from a social psychological and subsequently, a psychoanalytic point of view. After this, I will provide some examples. Finally, I will conclude with some reflections regarding the relationship between collusion and crime.

\section{What Is Collusion from a Social Psychological and a Psychoanalytic Perspective?}

Collusion is the central theme of social/organizational psychologist Jerry Harvey, who was known for his formulation of the Abilene paradox (Harvey 1988) where groups fail to act in line with the (unanimous yet private) preferences of their group members and even act in the opposite way. In his book entitled How come everytime I get stabbed in the back my fingerprints are on the knife (Harvey 1999), Harvey describes how individuals are complicit to their own downfall because they failed to speak out. Human beings need to be in meaningful contact with others and their fear of abandonment and 
separation form the core of this phenomenon. People tend to remain silent when they imagine that their opinion deviates from those of significant others. They entertain negative fantasies about the consequences especially as they fear rejection. Therefore, it remains untested whether indeed there is a diversity in ideas, preferences, interests and feelings. Since no one speaks out, the group members reinforce one another in their false beliefs, i.e., the beliefs that they incorrectly attribute to the other group members.

Thus, collusion in the psychological sense refers to a hidden dynamic among protagonists. The dynamic involves an implicit and often non-conscious collaboration that is aimed at mutually satisfying hidden needs and/or warding off fears (such as, finding approval, boosting one's self-esteem, avoiding rejection or exclusion, not being confronted with powerlessness or insecurity and so on). Protagonists share a joint desire to avoid a confrontation with a possibly painful or threatening reality. As a consequence, (real or imagined) differences in interests, preferences and identities are neglected or glossed over and parties may arrive at a premature or false consensus (Schruijer 2008a; Gray and Schruijer 2010). Certain contexts are more prone to collusive dynamics than others as they may trigger strong fears of being excluded, such as inreorganization or under fierce performance regimes. As previously mentioned, protagonists are often hardly conscious of their underlying fears. Outsiders see through the collusion faster than the protagonists themselves and they may help expose the collusive dynamics through confrontation. Furthermore, group members who have managed to keep their psychological independence may be capable of breaking through a collusive group dynamic. Once confrontation takes place, group members can become aware of the collusive dynamics.

Collusion is the opposite of task conflict where a diversity of interests, ideas and preferences are openly voiced and proactively worked with (Jehn 1995; Schruijer 2008a). The suppression of diversity is also a key characteristic of conformity and groupthink (Janis 1972), yet the dynamics of the latter two phenomena are different. In conformity and in groupthink, there are pressures from a known majority onto a known differently thinking individual. Thus, there are outside pressures, which in groupthink are also manifested in directive leadership. In collusion, the group members' fears and individual fantasies prevent them from speaking out and from testing reality. Thus, the pressures come from within (although in reality, the pressures from within and without can co-exist). Colluding group members may even privately agree, yet they find it impossible to communicate their agreement: in the Abilene Paradox, group members do just the opposite to what group members individually want to do or believe. Further, collusion in the social psychological sense is different from organizational secrecy (Costas and Grey 2014), which is a phenomenon described as the processes of intentional concealment of information. Collusion is a non-conscious dynamic. Some may see through it faster than others while some may see the contributing acts of others more clearly than how their own behavior reinforces the dynamics.

The term collusion has a long history in psychoanalysis, which pertains to a relationship between individuals who unconsciously confirm one another in one's behavior. Applied to the relationship between a psychoanalyst and an analysand, it has been defined as "a resistance between therapist and patient in which the transference and countertransference become interlocked in a tacit agreement to avoid a mutually fantasized catastrophe" (Karlsson 2004). An example could be a psychoanalyst who has a strong need for admiration and hence, cannot help the analysand to understand the latter's idealization of the analyst in terms of a defense of aggression (Stroeken 2000). Collusion can occur in any type of relationship. In the therapeutic world, couple dysfunction can be understood as projecting intrapsychic difficulties on the other who subsequently may act out some of these projections (e.g., Zeitner 2003).

Understanding collusion as a social defense against anxiety (Menzies-Lyth 1959), which occurs in a larger organizational and societal context, fits a systems-psychodynamic perspective on groups and organizations (Vansina and Vansina-Cobbaert 2008). A systems-psychodynamic perspective works within notions from psychoanalysis and systems theory to understand the (conscious and unconscious) emotional dynamics operating at the level of social systems while also finding ways to work with these. Long, who adopts a systems-psychodynamic perspective, has written about perverse cultures where 
collusive dynamics are a central feature. These dynamics underlie the manifest corruption in and of organizations. Perverse cultures are characterized by: (1) the realization of individual goals or pleasures at the expense of others; (2) simultaneously seeing while also denying reality; (3) the engagement of others as accomplices in the perversion; (4) turning a blind eye; and (5) a self-reinforcing cycle of perversions (Long 2008, p. 15).

A systems-psychodynamic perspective unearths the unconscious emotional underpinnings of collusion. It uses psychoanalytic understanding while trying to deindividualize collusion (and other) phenomena. Collusion needs to be understood at a social system level and not as individual behavior. The context of the social system is considered to be very important. Harvey also described collusion as a group or social system phenomenon. It is interesting to note that Jerry Harvey, like many of his contemporaries, such as Irving Janis, were familiar with psychoanalytic thinking as (social) psychologists, reflecting the less specialized training at the time as well as the openness to psychoanalysis, which is very different to current times (Schruijer and Curseu 2014).

\section{Some Examples}

I will present some examples where I was directly involved either as an action researcher or organizational member. Thus, I could sense and experience the dynamics. In my work on interorganizational collaboration (Schruijer 2008b), I have frequently encountered collusive dynamics. In various runs of a two-day simulation involving seven legally autonomous parties working around a regional development issue (Vansina et al. 1998), intended to help participants (managers and other practitioners) to learn about relational dynamics in an experiential way, it often proves increasingly difficult to engage in task conflict, needed to arrive at constructive plans that realize joint goals while also serving one's own interests. Having quite unsuccessfully dealt with the complexities, diversities and ambiguities, the participants instead settle for a vague and untested final deal and quickly wave away any doubt, critical remark or new piece of information that may be uttered during the last meeting. Thus, unrealistic deals are made as any deal is apparently considered better than no deal (although the simulation's instructions make it very clear that no deal is expected), even though this deal serves no one's interests and is based on false and unchecked assumptions. This reality does generally kick in during the one-day review after the actual simulation albeit slowly. Initially, individuals often think they have collaborated very well and seem happy with what they experience as successful agreements. It is only after the feelings of disappointment and/or shame are experienced that the defenses are dropped.

Another example is when I was asked to work with a group of contractors and the principal agent on the redevelopment of a major highway in the Netherlands (Schruijer 2015). Wanting to overcome the traditional win-lose climate, the protagonists had initiated an informal table that met regularly with all stakeholders present. The idea was to discuss the problems, mobilize the constituencies and deal with the concerns before escalation could occur at formal contract tables. It was an innovation for those involved and collaborative relationships were built among the various contractors and the governmental principal. However, as the parties became more and more careful not to destroy the burgeoning collaborative relationships, real concerns and potentially divisive issues disappeared from the discussion. Although parties intended to bring in their concerns, the meetings ended without much tension. For example, there was a growing concern among all stakeholders that they could not meet the deadline which they proudly had moved forward. Rather than addressing the issue and openly discussing the problems and possible solutions at the informal table as they had agreed to do, they acted as if nothing was the matter. The parties seemed satisfied and felt they were collaborating well. As such, these dynamics undermined the raison d'être of the well-intended informal table When interviewing parties afterwards, they were wondering why they had not brought in their pressing concerns. Once the collusive dynamics, which resulted in them not facing their reality, were addressed through outside interventions, the protagonists could recognize the dynamics that kept them trapped and they were able to subsequently deal with the issues. The tendency to collude in keeping important concerns out needs to be seen in light of a threatening context: (a) a major building fraud was still 
in the back of their minds; (b) a history of win-lose conflict as a consequence of tendering based on the lowest price existed; (c) protagonists, who sincerely wanted to show the world that collaboration between contractors on the one hand and the principal on the other was possible, were confronted with their respective constituencies who did not at all believe so; and finally (d) negative newspaper articles circulated concerning the financial and time excesses of large infrastructural projects.

Collusive dynamics can also be encountered at universities as I once experienced as an external examiner of a PhD committee. My negative assessment was met with hostility by one of the supervisors. I was requested to step down from the committee, which I refused. By then, I had found out that there was an ex-supervisor who had given up on this $\mathrm{PhD}$ project as, so I was told, it was doomed to fail. I asked for a response to my assessment from the supervisors, which I did not receive, although I was reassured by mail that an open discussion was to be held on the day of the defense (while the $\mathrm{PhD}$ was to be conferred anyhow, in line with the regulations, as all other examiners had approved of the thesis). I asked for the reports of the other examiners, which I did not receive. Furthermore, I requested that my report was to be sent to the other examiners which, as I later learned, never happened. I rang the dean, sharing my view that at least a discussion among committee members was needed. The dean commented that the correct procedure was followed so no intervention was needed. Days before the formal ceremony, I contacted the two other external examiners: one was surprised that he had not received my formal report while also expressing his doubts about the quality of the PhD. After the ceremony, the other examiner whispered in my ear that so much more was wrong with the thesis. No discussion among committee members took place on the day itself as the chair decided there was no time for that. Afterwards, the dean told me that the examination procedure was to be changed while one of the supervisors expressed his frustration over me sending my report to the address provided rather than to the supervisor informally. It struck me how all discussion was avoided during the whole process. Even the assessment procedure (consisting of soliciting only a "yes, the manuscript can proceed to the formal defense" or "no, it cannot" from the examiners) precludes the sharing and discussion of ideas. Systems, routines, regulations and the decisions of key actors all avoided a platform where opinions and ideas could be shared and reality could be tested. There was no shared interest to do so. I have analyzed this particular experience in more detail (Schruijer 2013) and situated it in a larger university context that implicitly seems to discourage negative assessments (as among other factors, a substantial output bonus for each successfully defended $\mathrm{PhD}$ is conferred to the university).

Other examples can be taken from different sectors. A recently published one that explicitly uses the term 'collusive dynamics' pertains to the child protection practice (Revell and Burton 2016), which has been criticized for professional negligence. The latter is attributed to collusive dynamics by Revell and Burton against the background of performance pressures. Practitioners have difficulties discussing the troublesome emotional aspects of their work with their supervisors while the latter fail to explore what makes it difficult to confront actual abuse as this may work against meeting the performance indicators. Well-elaborated examples of collusive dynamics in perverse cultures are provided by Long (e.g., Long Term Capital Management (LTCM) and Parmalat) herself (Long 2008). The consequences of the many examples provided above vary in seriousness. Not all examples result in corruption, although the collective denial of reality and acting upon such delusions can definitely be called perverse.

\section{Reflection}

The question remains-is collusion criminal? Unlike the general understanding of collusion as fraud or deceit, collusion in the psychological meaning is no crime. However, it is a phenomenon that may result in non-action, neglect, irresponsible, corrupt or other criminal behavior or may result in people collectively choosing the wrong course of action. In reality, individuals are often either held accountable or held culpable for the outcome of collusive dynamics. Individuals under whose jurisdiction the negative consequences occur are often taken off duty or dismissed. Those who are held to be culpable may have indeed acted culpably. Yet, if collusive dynamics are at play, punishing an individual will not change the climate under which culpable behavior may have occurred, although finding a culpable individual 
(or an innocent scapegoat) may help alleviate feelings of anger, shame and anxiety in the larger system. Pointing out and removing a bad apple may be sensible but it does not address the underlying dynamics that created the bad apple or at least allowed the bad apple to flourish.

Conflicts of Interest: The author declares no conflicts of interest.

\section{References}

Ayres, Ian. 1993. How cartels punish: A structural theory of self-enforcing collusion. Columbia Law Review 87: 295-323. [CrossRef]

Costas, Jana, and Christopher Grey. 2014. Bringing secrecy into the open: Towards a theorization of the social processes of organizational secrecy. Organization Studies 35: 1423-47. [CrossRef]

Gray, Barbara, and Sandra Schruijer. 2010. Integrating multiple voices: Working with collusion. In Relational Practices, Participative Organizing. Edited by Chris Steyaert and Bart Van Looy. Emerald: Bingley, pp. 121-35.

Harvey, Jerry B. 1988. The Abilene Paradox and Other Meditations in Management. Lexington: Lexington Books.

Harvey, Jerry B. 1999. How Come Everytime I Get Stabbed in the Back My Fingerprints Are on the Knife. San Francisco: Jossey-Bass.

Janis, Irving L. 1972. Victims of Groupthink. Boston: Houghton Mifflin.

Jehn, Karen A. 1995. A multimethod examination examination of the benefits and detriments of intragroup conflict. Administrative Science Quarterly 40: 256-82. [CrossRef]

Karlsson, Roger. 2004. Collusions as interactive resistances and possible stepping-stones out of impasses. Psychoanalytic Psychology 21: 567-79. [CrossRef]

Long, Susan. 2008. The Perverse Organization and Its Deadly Sins. New York: Routledge.

Menzies-Lyth, Isabel. 1959. The functions of social systems as a defence against anxiety: A report on a study of the nursing service of a general hospital. Human Relations 13: 95-121. [CrossRef]

Revell, Lisa, and Victoria Burton. 2016. Supervision and the dynamics of collusion: A rule of optimism? British Journal of Social Work 46: 1587-601. [CrossRef]

Schruijer, Sandra. 2008a. Samenwerking, Collusie en de rol van Devianten. Utrecht: Utrecht University.

Schruijer, Sandra. 2008b. The psychology of interorganizational relations. In The Oxford Handbook of Interorganizational Relations. Edited by Cropper Steve, Mark Ebers, Chris Huxham and Peter Smith Ring. New York: Oxford: Oxford University Press, pp. 417-40.

Schruijer, Sandra. 2013. Venalism in higher education: A systems-psychodynamic perspective. Organizational and Social Dynamics 13: 115-26.

Schruijer, Sandra. 2015. Like hedgehogs making love: Ups and downs in the relationship between a public body and private contractors in reconstructing a main Dutch highway. Paper presented at NIG Panel 13: Public Private Partnerships, Nijmegen, The Netherlands, November 5-6.

Schruijer, Sandra, and Petru L. Curseu. 2014. Looking at the gap between the social psychological and psychodynamic perspectives on group dynamics historically. Journal of Organizational Change Management 27: 232-45. [CrossRef]

Stroeken, Harry. 2000. Nieuw Psychoanalytisch Woordenboek. Meppel: Boom Koninklijke Uitgevers.

Van den Heuvel, Grat. 2005. The parliamentary enquiry on fraud in the Dutch construction industry collusion as concept between corruption and state-corporate crime. Crime, Law and Social Change 44: 133-51. [CrossRef]

Vansina, Leopold S., and Marie-Jeanne Vansina-Cobbaert. 2008. Psychodynamics for Consultants and Managers: From Understanding to Leading Meaningful Change. London: Wiley.

Vansina, L., T. C. B. Taillieu, S. G. L. Schruijer, W. Pasmore, and R. Woodman. 1998. 'Managing' multiparty issues: Learning from experience. In Research in Organizational Change and Development. Edited by William A. Pasmore, Abraham B. Shani and Richard W. Woodman. Greenwich: JAI Press, vol. 11, pp. 159-83.

Zeitner, Richard M. 2003. Obstacles for the psychoanalyst in the practice of couple therapy. Psychoanalytic Psychotherapy 20: 348-62. [CrossRef] 